\title{
How to Deal with the Damaged Kariba Dam
}

\author{
Shiwei Li \\ School of North China Electric Power University, Baoding 071000, China \\ 1771979536@qq.com
}

Abstract: The Kariba dam, which is constructed to provide power to Zambia and Zimbabwe, has been damaged seriously over the years so that it is urgent to solve this problem. This paper provides three main methods to address the situation. I illustrate the feasibility of each option by considering its potential costs and benefits, and it turns out that the third option, removing the existing Kariba Dam and replacing it with a series of ten to twenty smaller dams along the Zambezi River, is the optimal strategy to resolve the problem of the damaged dam and provide abundant supply of electric energy to the residents living along the Zambezi River as well. Then, I obtain three channel segments which are suitable to construct dams by analyzing the geographical environment and culture factors along the Zambezi River. Based on this, I establish the Analytic Hierarchy Progress (AHP) Model to determine the proportion of dams in the picked channel segments, which is determined by three main criteria and each criterion is related to two or three sub- criterions. With these factors, we get a specific proportion to distribute the small dams.

Keywords: the Kariba Dam, Analytic Hierarchy Progress (AHP)

\section{Introduction}

The Kariba Dam, constructed in 1955-59, with a storage capacity of $180 \mathrm{~km}^{3}$, extending over a length of about $300 \mathrm{~km}$, and having a surface area of some $5500 \mathrm{~km}^{2}$ at full supply level, is one of the largest dams in the world. The construction of Kariba Hydropower Station has eased the situation of power shortage which holds back economic progress in both Zambia and Zimbabwe and has greatly improved the living standards of people of Zambia. Besides, Lake Kariba has become a major area for fisheries as an additional effect of Kariba Hydropower Station.

However, nowadays the Kariba Dam is in a dangerous state. Opened in 1959, it was built on a seemingly solid bed of basalt. But, in the past 60 years, the torrents from the spillway have eroded that bedrock, carving a vast crater that has undercut the dam's foundations. Engineers are now warning that without urgent repairs, the whole dam will collapse. If that happened, a tsunami-like wall of water would rip through the Zambezi valley, reaching the Mozambique border within eight hours. The torrent would overwhelm Mozambique's Cahora Bassa Dam and knock out 40\% of southern Africa's hydroelectric capacity. Along with the devastation of wildlife in the valley, the Zambezi River Authority estimates that the lives of 3.5 million people are at risk.

\section{Three options to address the situation of the eroded Kariba Dam}

As the torrents from the spillway have been eroding the bedrock of the Kariba Dam over the sixty years, a number of options are available to the Zambezi River Authority that might address the situation. This paper focuses on three options which in particular are of interest to ZRA. 


\subsection{Contents of the Three Options}

Option 1: Repairing the existing Kariba Dam.

Option 2: Rebuilding the existing Kariba Dam.

Option 3: Removing the existing Kariba Dam and replacing it with a series of ten to twenty smaller dams along the Zambezi River.

\subsection{Comparison of the Three Options}

- In the view of potential cost, repairing the dam costs least money and time, the cost of the other two options consists of the daily maintenance cost, the demolition cost, the construction cost for the new identical dam and the cost of migration. Thus, the first option is economically best.

- From the perspective of system safety and reliability, obviously, the second and the third option are far better than the first one. A completely dam must be much stronger than the old one. Besides, it's easier to repair and maintain the small dam than the big one.

- Under the consideration of economic and social benefits, building a series of small dams can bring more benefits that a single big dam cannot bring, including facilitating the development of tourism, boosting local economy, promoting cultural exchange between nations, developing the shipping industry along Zambezi River and so on.

Taking all this factors into account, the third option, removing the existing Kariba Dam and replacing it with a series of ten to twenty smaller dams along the Zambezi River, proved be the best way to solve the problem of the seriously damaged dam completely.

\section{The Placement of the New Multi-Dam System}

After consulting a lot of data, it turns out that 17 small dams totally is the optimal number. When choosing the location of the series of dams, we suppose to considerate how to distribute them as well as how many dams should be constructed.

\section{1 Model Building}

In the upstream of Zambezi River, the flow velocity is slow, the terrain slopes gently which make it not worth to exploit hydropower resources, so that we choose to construct dams in middle and upper reaches, middle reaches and lower reaches. Then we choose to use the Analytic Hierarchy Progress to determine the proportion of dams under the circumstance that we don't know the total quantity of dams.

We list a table according to the criterions and sub-criterions that restrict the location of the series of dams.

Table 1: The factor should be considered in APH

\begin{tabular}{|c|c|c|c|}
\hline Criterions & Environment and Location & Economic Investment & Reservoir Storage \\
\hline Sub-criterion 1 & Human activities & Permanent land investment & Artificial regulation \\
\hline Sub-criterion 2 & Hydrology Resources & Resettlement Investment & precipitation \\
\hline Sub-criterion 3 & Topography & Total static investment & \\
\hline
\end{tabular}

Then, we build the site-selection APH evaluation system consisting of the target later, the criteria layer, the sub-criteria layer and scheme layer and draw structure chart in Figure 1. 


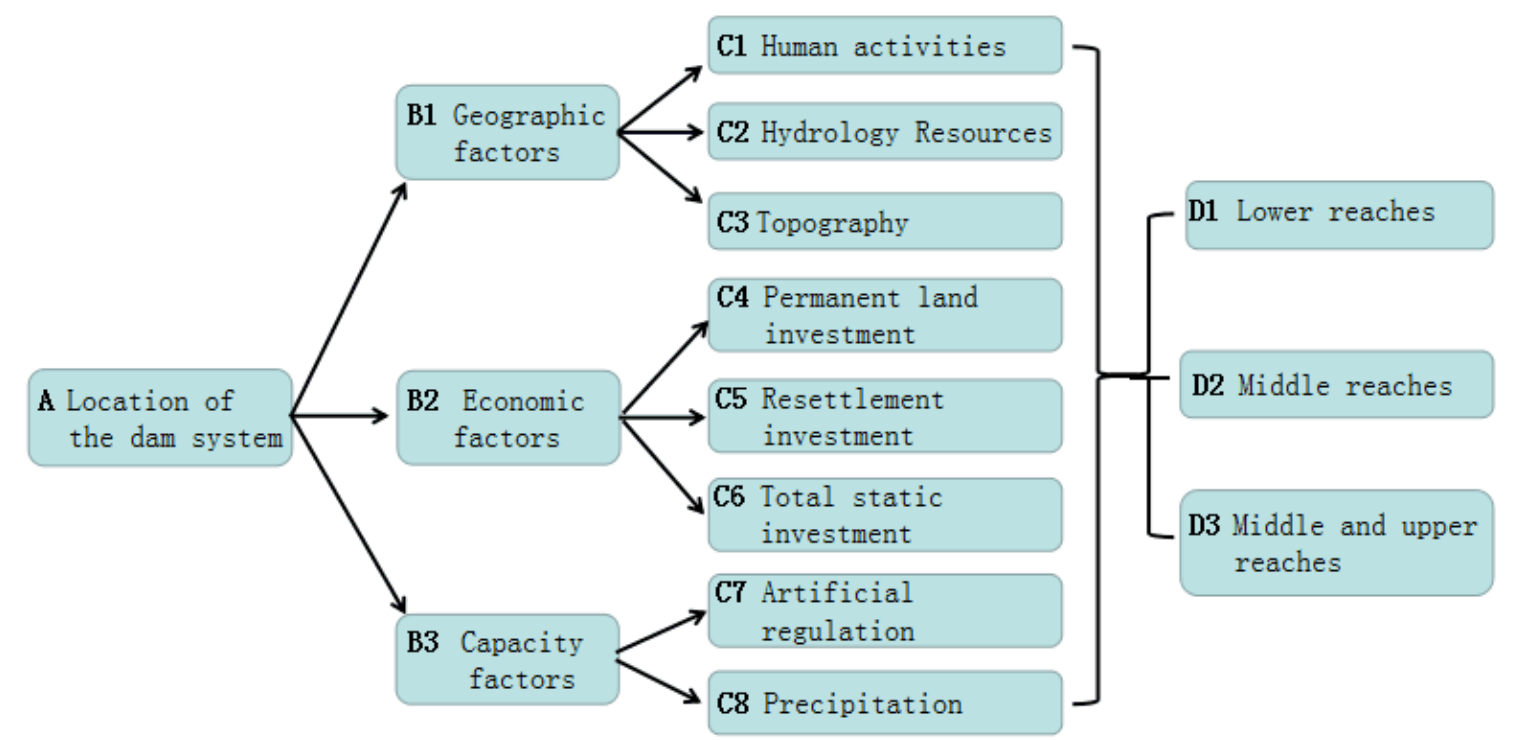

The target layer The criteria layer Sub-criteria layer

Scheme layer

Fig. 1 The structure chart

\subsection{Model analyzing}

From the above figure, we can sort out the importance degree of each element for the element which they determine by comparing every two elements.

Table 2: The importance degree among the criterions and sub-criterions

\begin{tabular}{|c|c|c|}
\hline Sequence & Factors & Importance degree \\
\hline 1 & A & $\mathrm{B} 2>\mathrm{B} 1>\mathrm{B} 3$ \\
\hline \multirow{3}{*}{2} & B1 & $\mathrm{C} 2>\mathrm{C} 3>\mathrm{C} 1$ \\
\hline & B2 & $\mathrm{C} 4>\mathrm{C} 5=\mathrm{C} 6$ \\
\hline & B3 & $\mathrm{C} 7>\mathrm{C} 8$ \\
\hline \multirow{8}{*}{3} & $\mathrm{C} 1$ & $\mathrm{D} 1>\mathrm{D} 2>\mathrm{D} 3$ \\
\hline & $\mathrm{C} 2$ & $\mathrm{D} 1=\mathrm{D} 2>\mathrm{D} 3$ \\
\hline & C3 & $\mathrm{D} 1>\mathrm{D} 2>\mathrm{D} 3$ \\
\hline & $\mathrm{C} 4$ & $\mathrm{D} 2>\mathrm{D} 1>\mathrm{D} 3$ \\
\hline & $\mathrm{C} 5$ & $\mathrm{D} 1>\mathrm{D} 2>\mathrm{D} 3$ \\
\hline & C6 & $\mathrm{D} 2>\mathrm{D} 1>\mathrm{D} 3$ \\
\hline & $\mathrm{C} 7$ & $\mathrm{D} 3>\mathrm{D} 2>\mathrm{D} 1$ \\
\hline & C8 & $\mathrm{D} 1>\mathrm{D} 2>\mathrm{D} 3$ \\
\hline
\end{tabular}

$\diamond \mathrm{X} 1>\mathrm{X} 2$ means the factor $\mathrm{X} 1$ is more important than the factor X2;X1=X2 means the factor X1

is as important as the factor $\mathrm{X} 2$

According to the above importance degree, we can get obtain the judgment matrix of each layer.

Table 3: The judgment matrix of each layer

\begin{tabular}{|c|c|c|c|}
\hline A & B1 & B2 & B3 \\
\hline B1 & 1 & $1 / 5$ & 3 \\
\hline B2 & 5 & 1 & 7 \\
\hline
\end{tabular}

\begin{tabular}{|c|c|c|c|}
\hline B1 & C1 & C2 & C3 \\
\hline C1 & 1 & $1 / 7$ & $1 / 3$ \\
\hline C2 & 7 & 1 & 5 \\
\hline
\end{tabular}

\begin{tabular}{|c|c|c|c|}
\hline B2 & C4 & C5 & C6 \\
\hline C4 & 1 & 7 & 7 \\
\hline C5 & $1 / 7$ & 1 & 1 \\
\hline
\end{tabular}

\begin{tabular}{|c|c|c|}
\hline B3 & C7 & C8 \\
\hline C7 & 1 & 7 \\
\hline C8 & $1 / 7$ & 1 \\
\hline
\end{tabular}




\begin{tabular}{|c|c|c|c|}
\hline B3 & $1 / 3$ & $1 / 7$ & 1 \\
\hline C1 & D1 & D2 & D3 \\
\hline D1 & 1 & 3 & 5 \\
\hline D2 & $1 / 3$ & 1 & 3 \\
\hline D3 & $1 / 5$ & $1 / 3$ & 1 \\
\hline
\end{tabular}
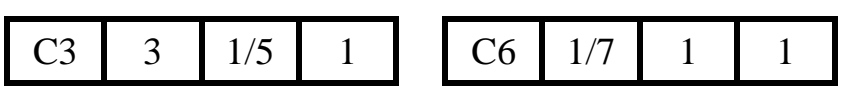

\begin{tabular}{|c|c|c|c|}
\hline C5 & D1 & D2 & D3 \\
\hline D1 & 1 & 3 & 5 \\
\hline D2 & $1 / 3$ & 1 & 3 \\
\hline D3 & $1 / 5$ & $1 / 3$ & 1 \\
\hline
\end{tabular}

\begin{tabular}{|c|c|c|c|}
\hline C2 & D1 & D2 & D3 \\
\hline D1 & 1 & 1 & 1 \\
\hline D2 & 1 & 1 & 1 \\
\hline D3 & 1 & 1 & 1 \\
\hline
\end{tabular}

\begin{tabular}{|c|c|c|c|}
\hline C3 & D1 & D2 & D3 \\
\hline D1 & 1 & 3 & 5 \\
\hline D2 & $1 / 3$ & 1 & 3 \\
\hline D3 & $1 / 5$ & $1 / 3$ & 1 \\
\hline
\end{tabular}

\begin{tabular}{|c|c|c|c|}
\hline C4 & D1 & D2 & D3 \\
\hline D1 & 1 & $1 / 3$ & $1 / 5$ \\
\hline D2 & 3 & 1 & $1 / 3$ \\
\hline D3 & 5 & 3 & 1 \\
\hline
\end{tabular}

\begin{tabular}{|c|c|c|c|}
\hline C6 & D1 & D2 & D3 \\
\hline D1 & 1 & $1 / 3$ & 3 \\
\hline D2 & 3 & 1 & 5 \\
\hline D3 & $1 / 3$ & $1 / 5$ & 1 \\
\hline
\end{tabular}

\begin{tabular}{|c|c|c|c|}
\hline C7 & D1 & D2 & D3 \\
\hline D1 & 1 & $1 / 3$ & $1 / 5$ \\
\hline D2 & 3 & 1 & $1 / 3$ \\
\hline D3 & 5 & 3 & 1 \\
\hline
\end{tabular}

\begin{tabular}{|c|c|c|c|}
\hline C8 & D1 & D2 & D3 \\
\hline D1 & 1 & 3 & 5 \\
\hline D2 & $1 / 3$ & 1 & 3 \\
\hline D3 & $1 / 5$ & $1 / 3$ & 1 \\
\hline
\end{tabular}

3. 3 Results

- Based on the judgment matrix, we calculate the proportion of each factor with MATLAB programming language.

Table 4: The Proportion of Each Factor

\begin{tabular}{|c|c|c|c|c|}
\hline Criterions & $\begin{array}{c}\text { Environment and } \\
\text { Location }\end{array}$ & $\begin{array}{c}\text { Economic } \\
\text { Investment }\end{array}$ & $\begin{array}{c}\text { Reservoir } \\
\text { Storage }\end{array}$ & \multirow{2}{*}{$\begin{array}{c}\text { Total sort } \\
\text { weight }\end{array}$} \\
\cline { 1 - 3 } $\begin{array}{c}\text { Proportion of } \\
\text { criterions B }\end{array}$ & 0.6544 & 0.2289 & 0.1167 & \\
\hline
\end{tabular}

Table 5: The Proportion of Sub-criterion

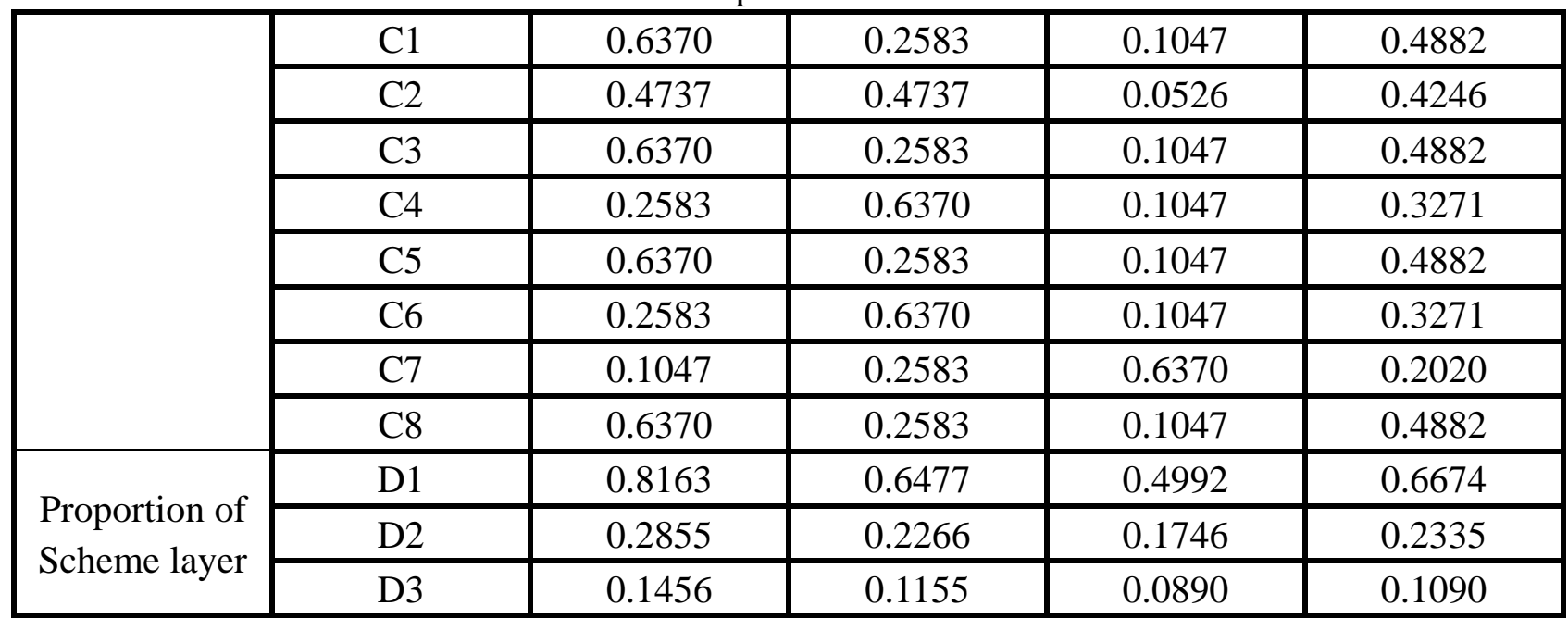

- We calculate the relative parameters to test the consistency of each layer with the data in

Table 4 and Table 5 to judge the consistency of the judgment matrix.

There are some formulas to calculate $C I$ and $C R$.

$$
C I=\frac{\lambda_{\max }-\mathrm{n}}{n-1}
$$

Where:

$\lambda_{\text {max }}$ is the largest eigenvalue of every factor;

$\mathrm{n}=3$ is the number of the factors in the criteria layer;

CI is the consistency indicators of each layer. 


$$
C R=\frac{C I}{R I}
$$

Where

$R I=0.58$ is the random consistency index of each layer;

$C R$ is the consistency ratio of each layer.

By analyzing the above result, we can find that the $C R$ of each layer is less than 0.1 , which means the judgment matrix meets the consistency demand and we can consider the result we get is right.

- As we prove the previous analysis is right, we can obtain the proportion of each scheme by synthesizing the elements of a single layer from the top to bottom.

Table 6: Proportion of each scheme

\begin{tabular}{|c|c|c|c|}
\hline Scheme & D1 & D2 & D3 \\
\hline Proportion & $66.74 \%$ & $23.35 \%$ & $10.9 \%$ \\
\hline
\end{tabular}

According to the analysis above, the site selection of the dams is :

Build $66.74 \%$ dams in the downstream;

Build 23.35\% dams in the midstream;

Build 10.9\% dams in the middle and upper reaches.

\section{Conclusions}

In this paper, we have solved two problems, one is choosing which method to settle the matter of the seriously damaged Kariba Dam, the other is choosing the location of the small dams. We have used the Analytic Hierarchy Progress model to analyze the factors which include geographic factors, economic factors and capacity factors that determine where the series of dams should locate. Considering the water-head along the Zambezi River, we build three dams in the middle and upper reaches, three dams in the midstream and ten dams in the downstream.

While our approaches and models were effective and produced results, there remain several types of model weaknesses, one of them is that the calculation of our model is complex. The factors we considerate is as much as we could come up with in the APH model to make the model more close to the reality, however, at the same time, it brings 12 judgment matrixes, and each one of them requires a number of calculations.

\section{References}

[1] Committee on the safety of existing dams, et al. Safety of existing dams (Evaluation and improvement), chapter 3, National Academy Press, Washington D C,1983

[2] Thun J L V. Application of decision analysis techniques in dam safety evalvation and modification. Proc of the ICOSD, C2.2. Rotterdam,1984: 265 271

[3] Information on https://en.wikipedia.org/wiki/Kariba_Dam

[4] Jiazheng Pan. Harmonious society and pumped storage[C]//Further Understanding of Pumped Storage Power Stations. Special Committee on Pumped Storage. 2006. 